\title{
AITP 2019 - ANO INTERNACIONAL DA TABELA PERIÓDICA DOS ELEMENTOS QUÍMICOS
}

\author{
Henrique E. Toma ${ }^{a}$ \\ anstituto de Química, Universidade de São Paulo, 05508-000, São Paulo - SP, Brasil
}

Recebido em 04/02/2019; aceito 19/03/2019; publicado na web 28/03/2019

\begin{abstract}
IYPT 2019 - INTERNATIONAL YEAR OF THE PERIODIC TABLE OF THE CHEMICAL ELEMENTS. United Nations elected 2019 a year devoted to the Periodic Table of the Elements, in deference to the original contribution by Dmitri Ivanovich Mendeleev in 1869. Since then, the impact of the Periodic Table in Science has been tremendous, becoming an icon today as the Chemistry Portal, leading to a better acquaintance of the chemical elements. In this article, modern aspects of the Periodic Table of the Elements are presented, complementing an existing historical presentation in this Journal, with special emphasis on the quantum distribution models and on the remarkable role of the elements in Science and Nanotechnology.
\end{abstract}

Keywords: periodic table; IYPT; nanotechnology; bioinorganic chemistry; isotopes.

\section{INTRODUÇÃO}

A ONU elegeu 2019 o Ano Internacional da Tabela Periódica, ${ }^{1}$ em deferência à primeira publicação da Tabela organizada por Dmitri Ivanovich Mendeleev, ${ }^{2}$ em 1869. Passaram-se 150 anos deste então, e hoje ela está presente nas salas de aula e em quase todos os livros de Química. Para os não químicos, pode parecer estranho essa escolha temática da ONU: uma Tabela? Para os cientistas, porém, essa homenagem é muito louvável, e proporciona uma excelente oportunidade para falar de Ciência e principalmente da Química, além de mostrar como ela é fundamental em nossa vida. De fato, atualmente, a Tabela Periódica é um Portal do Conhecimento. Nela estão todos os elementos químicos conhecidos. Assim como as letras do alfabeto compõem as palavras, os elementos compõem todas as substâncias e materiais que conhecemos e proporcionam conforto e qualidade vida através da Química. Sob o símbolo de cada elemento existe uma longa história de descobertas, muitos Prêmios Nobel e também muitos sonhos a embalar a nossa vida.

O volume de dados históricos sobre a Tabela Periódica é impressionante, e para poupar espaço cabe uma recomendação enfática de consulta ao excelente artigo publicado por Tolentino, Rocha-Filho e Chagas ${ }^{3}$ em 1997, na Química Nova. Mas, além da retrospectiva histórica, ${ }^{4,5}$ existem outros aspectos que levaram a ONU a decidir pelo tema. De fato, hoje a Tabela Periódica transcende os fatos de sua criação, ela é um ícone, - o verdadeiro Portal da Química.

A forma de lidar com os elementos está mudando com as recentes imersões da Ciência no mundo Nano, - dimensão que é a mais próxima da escala atômica. A cada dia estão sendo descobertas novas formas elementares, que só podem ser vistas na escala nanométrica, ${ }^{6}$ como é o caso das nanoespécies de carbono como os fullerenos, nanotubos, grafeno, nanodiamante, e pontos quânticos de carbono. Com isso estão surgindo materiais mais resistentes que o aço, películas condutoras com espessura de uma molécula, superfícies à prova de riscos, sensores e elementos ópticos praticamente invisíveis, e novos medicamentos. E os resultados já estão ao nosso alcance, nos celulares e smartfones, nos aparelhos de TV cada vez mais finos e leves, nos computadores, e nos sensores que monitoram quase tudo que podemos imaginar.

O próprio ouro milenar, que sempre foi símbolo de riqueza, com seu brilho amarelo (dourado), na escala nano ganha outra cor,

*e-mail: henetoma@iq.usp.br vermelha, sem perder a nobreza. O vermelho das nanopartículas de ouro provém da oscilação dos elétrons de superfície quando atingidos pela luz, comportando-se como ondas ou plásmons. Isso acontece porque a luz é uma radiação eletromagnética conduzida pelo fóton que se propaga no espaço transportando campos elétricos e magnéticos oscilantes. Os elétrons das nanopartículas de ouro respondem aos campos elétricos oscilantes da luz, mas a eficiência máxima com que isso ocorre e que leva à ressonância, depende do ambiente local (dielétrico) em que se encontram. Quando se altera o ambiente químico ao redor da nanopartícula acontecem muitas coisas, incluindo mudanças de cor, geralmente de vermelho para azul. É assim que as nanopartículas de ouro sinalizam a presença de moléculas, fármacos e células, além de refletir uma luz que pode ser captada e trabalhada pelos instrumentos, permitindo chegar à detecção de apenas uma única molécula na superfície. No organismo, seu direcionamento por ser dirigido por meio de anticorpos até a célula cancerosa, e isso pode ser usado para sinalizar tumores e até destruí-los sob ação da luz. Essas nanopartículas são de fato teranósticas, associando terapia e diagnóstico. Tudo isso já é possível com esse elemento bem conhecido de todos, ainda considerado inerte e inócuo, porém que adquire nova personalidade quando em uma escala dimensional bem menor do que estamos acostumados.

\section{UMA TABELA PERIÓDICA REAL?}

Pode ser interessante observar diretamente os elementos na Tabela Periódica, como a que está exposta no Instituto de Química da USP (Figura 1). É incrível descobrir que o sódio metálico puro brilha tanto quanto a prata, que o bismuto metálico reflete os belos tons do arco-íris, e que o gálio até parece mercúrio. E ainda, que cada elemento tem suas idiossincrasias: por exemplo, assim como o ouro que adquire tons distintos na escala nano, o estanho metálico que embeleza os objetos de arte e utensílios com seu brilho fosco, reduz-se a pó em baixas temperaturas. No livro, os botões de Napoleão, ${ }^{7}$ as temperaturas congelantes da Rússia teriam pulverizado os botões de estanho usado nas roupas, deixando os soldados expostos, com o dilema de lutar ou de se manter coberto. Cogita-se que esta seria a causa deste grande comandante ter perdido a guerra. Mas tem muitas curiosidades interessantes sobre os elementos, e que foram bem explorados pelo jornalista Theodore Gray em seu livro, The Elements. ${ }^{8}$

Nessa Tabela, em particular, o selênio elementar recobre um cilindro de alumínio, e aparece como um revestimento violeta brilhante 


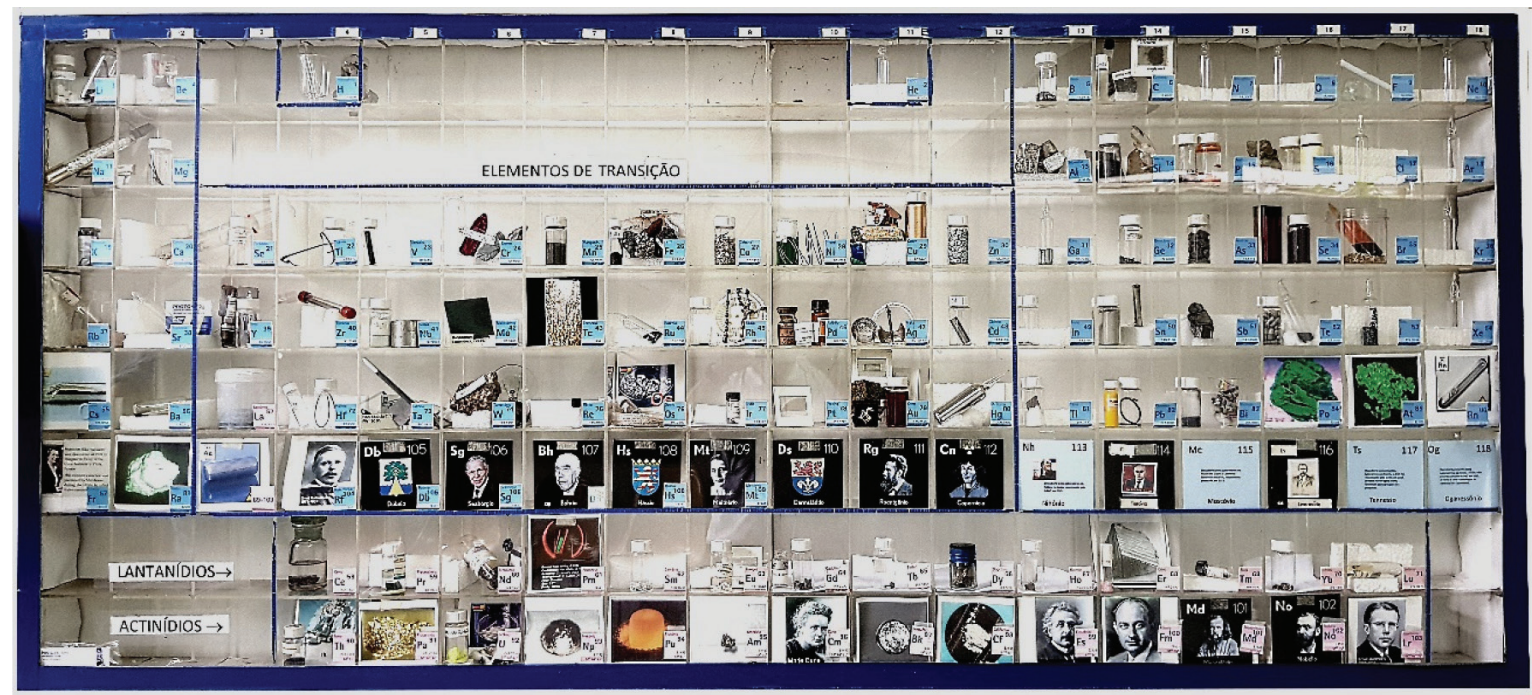

Figura 1. Tabela Periódica representando os elementos químicos em sua forma pura ou natural, exposta no Instituto de Química da Universidade de São Paulo (dimensão $1 m \times 2 \mathrm{~m}$ )

e inconfundível. O que poucos sabem, é que esse cilindro foi tirado de um cartucho de toner usado, de uma máquina de xérox. Quando a luz incide sobre esse elemento, ele responde emitindo elétrons que são captados pelo alumínio, deixando o local com carga positiva. É isso que provoca a atração das partículas do toner, depositando-as sobre a superfície, para depois serem transferidas para o papel de impressão e gerar a cópia xerográfica.

O mercúrio permanece enigmático como sempre, brilhante e fluído, porém escondendo o temor levantado nas últimas décadas, pelos seus efeitos nocivos sobre a vida. O brilho metálico líquido que já foi usado para recobrir grandes refletores ópticos em telescópios, também inspirou filósofos e alquimistas a considerar o elemento como algo primordial ou essencial. Foi até testado como elixir da longa vida, mas acabou levando à morte prematura de Qin Shi Huang Di (259-210 a.C.), o primeiro imperador da China unificada, entre 221 a 210 a.C. Restaram, porém, nada menos que os magníficos soldados de terracota, a muralha da China e a descoberta da pólvora, como feitos para relembrar sua existência. Mas a favor do mercúrio está a história do desenvolvimento da Química, com os avanços conseguidos desde Lavoisier, o surgimento da polarografia, e de produtos odontológicos, farmacêuticos e de laboratório, incluindo o termômetro, os quais estão sendo substituídos gradualmente por sucedâneos menos tóxicos. Sua afinidade por ouro tem sido uma desgraça nos garimpos clandestinos e na reciclagem não qualificada realizada por amadores, nos centros urbanos.

É interessante comparar o aspecto do cloro gasoso, amarelo pálido, com o líquido marrom-avermelhado fumegante que marca a aparência do bromo, e os belos cristais violetas do iodo. Eles proporcionam um exemplo claro da evolução das propriedades físicas com o aumento da massa molecular. E curiosamente, nesse sentido, Mendeleev estava correto: as massas dos elementos também são importantes.

\section{A VERSÃO ATUAL DA TABELA PERIÓDICA}

A Tabela Periódica atual é um pouco diferente daquela publicada por Mendeleev há 150 anos, e encerra um conceito completamente diverso, isto é, o uso de números atômicos em vez de massas atômicas. Para entender isso, temos que voltar até a época de Lavoisier (1789), ${ }^{4}$ quando as análises químicas dos compostos permitiram chegar com razoável precisão até as massas atômicas dos elementos, graças às leis das proporções definidas de Proust (1799) e das proporções múltiplas de Dalton (1803). ${ }^{5}$ Por isso, as massas atômicas disponíveis eram os melhores atributos da época para estabelecer a identidade e fazer a diferenciação dos elementos. No mesmo ano em que Mendeleev publicou sua Tabela com base nas massas atômicas e na similaridade química, ou até um pouco antes, Julius Lothar Meyer ${ }^{9}$ (1864) introduziu de forma brilhante a comparação dos elementos usando a valência, inspirado na Teoria de Kekulé. ${ }^{5}$ Assim, as características de combinação (valência) foram contempladas na similaridade dos elementos, explicando constatações anteriores, como as tríades de Döbereiner (1829) ${ }^{5}$, exemplificada pelo cloro, bromo e iodo, ou pelo lítio, sódio e potássio. O agrupamento por similaridade química também foi utilizado por Mendeleev, e isso tornou-se notório quando deliberadamente preferiu inverter a ordem dos elementos telúrio (massa atômica 127) e iodo (massa atômica 126) em sua Tabela Periódica então composta por 59 elementos. Entretanto, foi a capacidade de previsão da existência de novos elementos, como o gálio e o germânio que deu credibilidade à Tabela Periódica de Mendeleev. Estes foram descobertos por Lecoq de Boisbaudran em 1875 e Clemens Winker em 1886, respectivamente. ${ }^{5}$ Havia ainda espaço para uma família inteira de elementos, os gases nobres, que acabaram sendo descobertos por Willliam Ramsay em $1898 .^{5}$

A Tabela Periódica atual é baseada na sequência de números atômicos, ditada pelo número de prótons existentes no átomo. Portanto, ela incorpora a evolução da era atômica, desde a descoberta da radioatividade por Henry Becquerel (1895), ${ }^{5}$ das emissões radioativas e existência de isótopos (Frederick Soddy), ${ }^{5}$ e principalmente, das correlações espectrais com um número inteiro (Henry Moseley, 1913 $)^{5}$ que mais tarde tornou-se o número atômico. Vieram depois o modelo atômico de Rutherford, com o átomo nuclear, seguido pela visão pré-quântica de Bohr descrevendo os átomos com níveis discretos de energia.

A Tabela Periódica atual reflete a periodicidade das propriedades atômicas que podem ser explicadas pelo modelo quântico dos átomos. Esse modelo surgiu na década de 1920, com os elétrons distribuídos em níveis energéticos, ocupando regiões espaciais denominadas orbitais, os quais receberam as denominações $\mathbf{s , ~} \mathbf{p}, \mathbf{d}, \mathbf{f}$. Deste então, a ocupação dos orbitais passou a ser o conceito lógico que rege a Tabela Periódica, pois ela dita a configuração eletrônica dos átomos. Contudo a sequência de colocação dos elétrons nos átomos não é tão simples, pois depende não só da energia de cada nível ou camada, mas também do tipo de orbital envolvido. Note-se que enquanto os elétrons são atraídos pelo núcleo, eles se repelem mutuamente por 
forças eletrostáticas. $\mathrm{O}$ balanço entre as forças atrativas e repulsivas depende na natureza dos orbitais, ou seja de sua distribuição espacial. Além disso, o princípio de Pauli estabelece a distribuição dos spins, que é outro fator muito importante nas configurações eletrônicas. Por isso, a ordem de preenchimento das camadas pode sofrer variações, principalmente quando entram em jogo os orbitais d e f, e isso está refletido na Tabela Periódica.

Apesar de o número atômico expressar o número de prótons no núcleo, as semelhanças químicas decorrem da distribuição dos elétrons nos átomos, ou seja, da configuração eletrônica. Contudo, no átomo, o número de prótons é sempre igual ao número de elétrons e isso permite manter o uso do número atômico como identificador do elemento. Enquanto o número de elétrons varia quando o átomo passa para a forma de íon (cátion ou ânion), o número de prótons permanece inalterado, mantendo a identidade do elemento químico.

Geralmente é a última camada eletrônica que determina a posição dos elementos na Tabela periódica. Por exemplo, os elementos com um elétron $\mathbf{s}$ na última camada $\mathbf{n}$, isto é ns $^{1}$ estão alinhados na coluna 1 e os elementos $n s^{2}$ ficam na coluna 2. Pela ordem energética, os elementos seguintes deveriam ter a configuração $n s^{2} n p^{x}(x=1$ a 8). Entretanto, nos metais de transição, ocorre inversões energéticas decorrentes das diferentes repulsões intereletrônicas envolvendo os orbitais $\mathbf{d}$, e f, em relação aos orbitais $\mathbf{s}$ e $\mathbf{p}$. A configuração representativa da última camada energética (camada de valência) passa a ser $(n-1) d^{x} n s^{2}$ para os elementos de transição típicos, ou $(n-1) d^{x+1} n s^{1}$ quando x se aproxima de 4 ou 9 (também conhecido como efeito de configuração completa ou semicompleta), ou eventualmente 8 , como no caso do Pd, cuja configuração de valência é $4{ }^{10} \mathrm{em}$ vez de $4 \mathrm{~d}^{8} 5 \mathrm{~s}^{2}$. Essa regra não é absoluta, pois na Pt a configuração se mantém $5 \mathrm{~d}^{9} 6 \mathrm{~s}^{1}$ em vez de $5 \mathrm{~d}^{10}$. Nos elementos lantanídios e actinídios, a configuração representativa de valência é $(n-2) f^{x}(n-1) s^{2} p^{6} n s^{2}$.

Se a Tabela de Mendeleev tivesse surgido 50 anos depois, já na era quântica, talvez ela tivesse a forma proposta por Charles Janet em 1928 (Figura 2) com base nas configurações eletrônicas dos elementos:

Outra Tabela interessante, proposta por Hugh Christopher Longuet-Higgins ${ }^{10}$ em 1957 (Figura 3), reproduz diretamente a ordem de preenchimento dos orbitais pelo princípio Auf-bau, ou de construção, e é muito interessante do ponto de vista pedagógico por destacar a natureza dos orbitais de valência.

Entretanto, a despeito da lógica da distribuição quântica usada por Charles Janet e Longuet-Higgins, a Tabela periódica que utilizamos atualmente foi claramente inspirada em Mendeleev e apresentada pela primeira vez pelo químico americano Horace Groves Deming ${ }^{11}$ em 1923, em seu livro de Química Geral. De fato, Deming manteve a sequência de Mendeleev, porém trocou os números de massa pelos números atômicos, e estabeleceu uma distribuição em 18 colunas. Essa distribuição expressa a ocupação dos orbitais $\mathbf{s , ~} \mathbf{p}$ e $\mathbf{d}$ na representação dos blocos de elementos correspondentes, com 2, 6 e 10 elétrons, ou 18 no total. Os elementos do bloco f ficaram separados do conjunto, na parte inferior da Tabela, provocando uma interrupção da sequência natural de número atômicos. Essa tabela, com um formato mais compacto que os análogos quânticos, foi rapidamente assimilada pelos fornecedores de produtos químicos e instrumentos, os quais ampliaram sua divulgação através de posters e quadros para fixação em paredes e salas de aulas, como se observa até hoje. Na identificação das 18 colunas, Deming usou uma notação A e B para diferenciar os elementos representativos (blocos principais) dos elementos de transição (bloco do meio). Essa diferenciação persistiu até 1988 , quando foi suprimida pela IUPAC. ${ }^{12}$

\section{OS NOVOS ELEMENTOS NA TABELA PERIÓDICA}

Até 1937, havia um espaço vazio entre os elementos molibdênio e rutênio. Esse elemento, de número atômico 43, foi descoberto por Emílio Gino Segré, na Universidade de Palermo, a partir da análise de uma placa de molibdênio que havia sido bombardeada com núcleos de deutério no Lawrence Radiation Laboratory da Califórnia. Era o elemento abaixo do manganês, que faltava na Tabela Periódica. Sua radioatividade com um tempo de meia vida de 211 mil anos explica sua ausência entre os elementos encontrados na natureza, decorridos alguns bilhões de anos. Assim, o Tecnécio foi o primeiro elemento artificial a ser incorporado na Tabela Periódica.

A próxima leva de elementos foi sintetizada entre os anos 1950 e 1970 principalmente pela equipe de Glenn Theodore Seaborg na Califórnia, por meio de colisões entre núcleos atômicos em aceleradores nucleares. Seaborg inaugurou uma nova série de elementos após o urânio, estabelecendo um grupo específico da Tabela Periódica, que deveria começar com o tório (Th), protactínio (Pa) e urânio (U). Após a equipe de Seaborg ter isolado o plutônio, as descobertas foram se sucedendo com o amerício $(\mathrm{Am})$, cúrio $(\mathrm{Cm})$, berquélio (Bk), califórnio (Cf), einstênio (Es), férmio (Fm) e mendelévio (Md). Essa série que termina com o lawrêncio (Lr, 103), forma o grupo de elementos conhecidos como actinídios, e seu enquadramento em

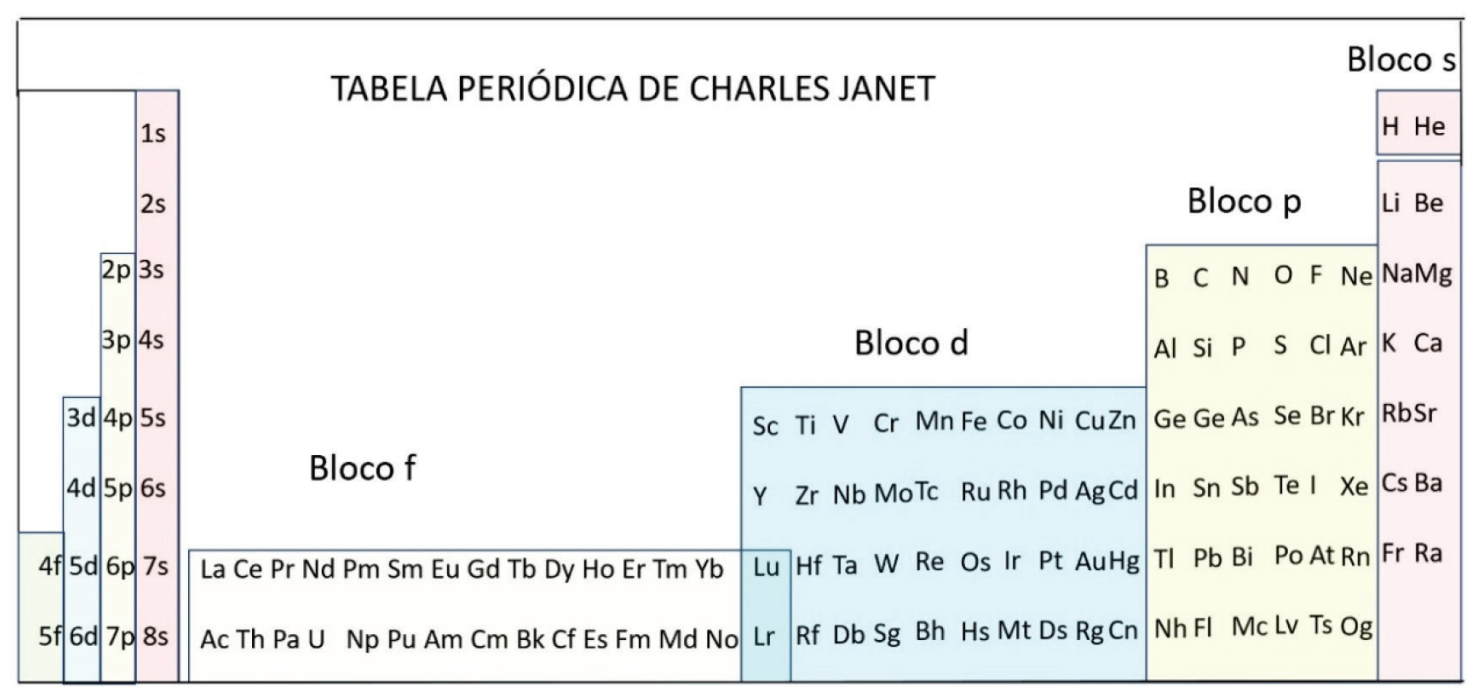

Figura 2. Tabela Periódica de Charles Janet, com os elementos colocados na ordem dos números atômicos, porém inspirado na distribuição dos elétrons nos átomos de acordo com a recém criada teoria quântica (1928). 
TABELA PERIÓDICA DE LONGUET-HIGGINS

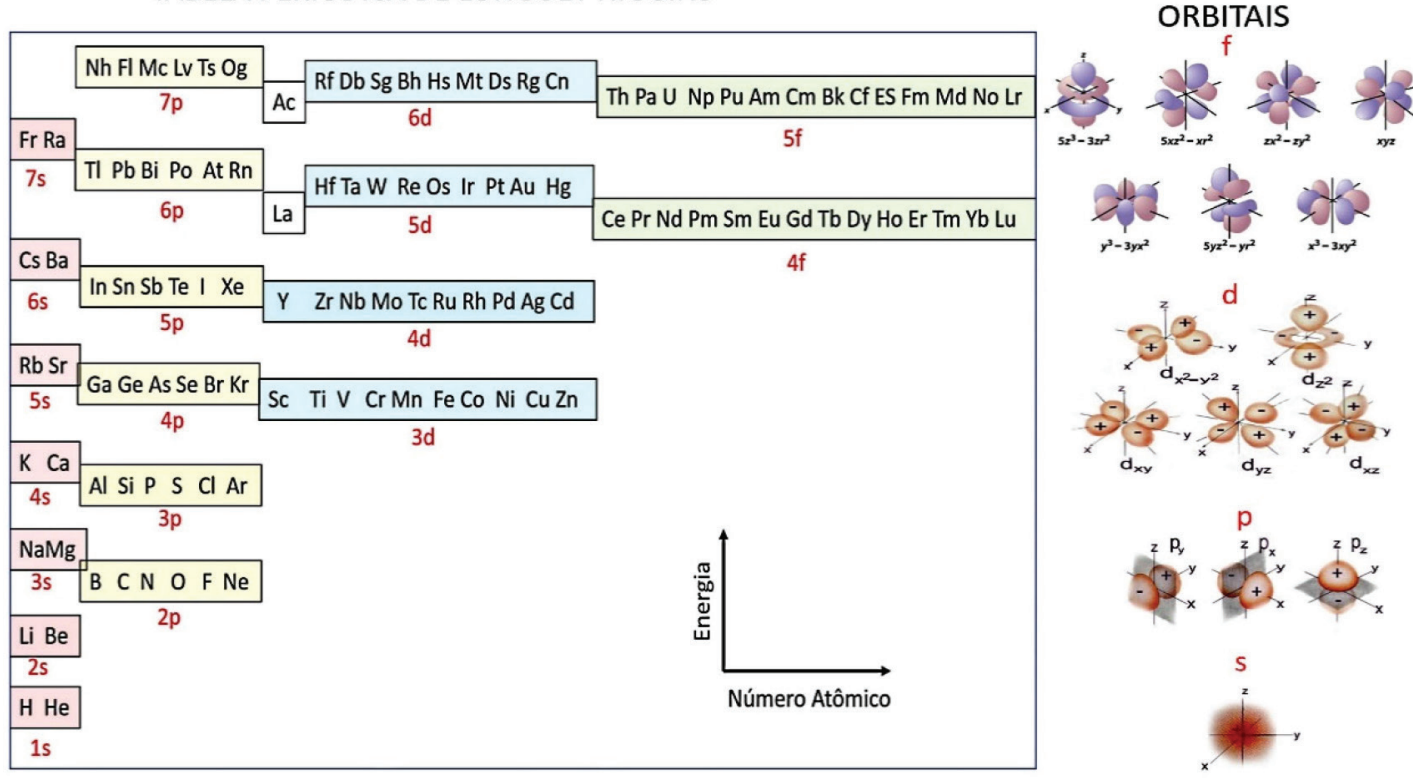

Figura 3. Tabela periódica de Longuet-Higgins com os elementos dispostos segundo a ordem de preenchimento orbital no esquema auf-bau, de baixo para cima, porém no sentido diagonal, deixando aparente os últimos orbitais semipreenchidos (lustrados à direita), responsáveis pelo estado de valência.

separado é bem justificado pelas Tabelas Periódicas inspiradas nas teorias quânticas. Eles formam os elementos do grupo $5 \mathrm{f}$ (Figura 3).

Muito se aprendeu na química nuclear com o estudo desses elementos artificiais, principalmente a existência de ilhas de estabilidade na correlação entre os números de massa e os números atômicos. Novos elementos foram previstos em função dessas ilhas, e confirmados na última década com a síntese desses elementos superpesados que faltavam para completar a última linha da Tabela Periódica. O elemento nihônio (113) foi sintetizado pelo bombardeamento de núcleos de elementos pesados como o bismuto $(Z=83)$, com átomos de zinco $(Z=30)$ nos aceleradores lineares da Riken no Japão. Embora a fusão de partículas pesadas seja considerada bastante improvável, em alguns casos a colisão pode resultar em transientes como o nihônio (113), cujo tempo de vida é de alguns milésimos de segundo. Esse elemento sofre quatro decaimentos alfa sucessivos, gerando o dúbnio, Db. Foi essa cadeia de transformações que forneceu a pista que levou à validação da descoberta do novo elemento. Os elementos 114 (fleróvio, Fl), 115 (moscôvio, Mc), 116 (livermório, Lv), 117 (tenesso, Ts), e 118 (oganessônio, Og) também foram sintetizados de forma semelhante, em aceleradores de partículas em Dubna (Rússia), Califórnia, e Tennessee (Estados Unidos).

\section{NOVAS VERSÕES DA TABELA PERIÓDICA}

Hoje, existem várias dezenas de design para a Tabela Periódica, projetando com criatividade diversos aspectos da distribuição dos elementos e sua importância, nos mais diferentes formatos, incluindo até design cósmico. Elas podem ser consultadas na Internet Database of Periodic Tables,${ }^{13}$ organizada especialmente para a celebração internacional de 2019. Destaque especial pode ser dado para uma Tabela Periódica que reúne os descobridores dos elementos, com suas respectivas fotografias preenchendo os espaços pertinentes. ${ }^{14}$ Recentemente a IUPAC publicou a Tabela Periódica dos Isótopos, incluindo a distribuição isotópica dos elementos representada em pequenos círculos, com seus diagramas do tipo pizza. ${ }^{15}$ Esses dados também foram introduzidos em colunas coloridas inseridas por este autor na Tabela Periódica convencional, para preservar o seu formato. ${ }^{16}$

A Tabela Periódica da Vida, reproduzida na Figura 4, é uma proposta do autor apresentada no livro de Química Bioinorgânica. ${ }^{17} \mathrm{~A}$
Tabela mostrada, é uma versão que inclui a distribuição isotópica dos elementos para auxiliar na análise dos espectros de massa. Ela coloca em evidência os elementos segundo suas abundâncias nos sistemas biológicos, diferenciando os elementos de construção molecular $(\mathrm{H}$, $\mathrm{C}, \mathrm{N}, \mathrm{O}, \mathrm{P}$ ) que compreendem de 1 a $60 \%$ na constituição dos seres vivos, dos elementos eletrolíticos $(\mathrm{Na}, \mathrm{K}, \mathrm{Cl})$ e de suporte $(\mathrm{Ca}, \mathrm{Mg}$, S) perfazendo 0,01 a $1 \%$, e dos elementos traços como V, Cr, Mn, Fe, $\mathrm{Co}, \mathrm{Ni}, \mathrm{Cu}, \mathrm{Zn}, \mathrm{Mo} \mathrm{e} \mathrm{W}$, presentes abaixo de $0,01 \%$ e respondem pela catálise na maioria dos processos enzimáticos. Também são contemplados elementos usados na medicina, como metalodrogas e agentes marcadores e de contraste. Sua presença na Tabela deverá se ampliar consideravelmente, com os avanços da Química Bioinorgânica.

Uma publicação recente de Tabela Periódica ${ }^{13}$ chamou a atenção para a possível escassez natural, em futuro próximo, de elementos químicos como Zn, Ga, Ge, In, Ag, Hf, Ta, Sr, Y, Te, e As, ou para a escassez provocada pela demanda crescente de $\mathrm{Cr}, \mathrm{Co}, \mathrm{Rh}, \mathrm{Ru}, \mathrm{Pd}$, $\mathrm{Pt}$, Os, Ir, Dy, Cd e U, em processos tecnológicos. Também ressalta outros elementos como Li, $\mathrm{Cu}, \mathrm{B}, \mathrm{Mg}, \mathrm{P}, \mathrm{Sc}, \mathrm{V}, \mathrm{Mn}, \mathrm{Ni}, \mathrm{Se}, \mathrm{Zr}, \mathrm{Nb}$, $\mathrm{Mo}, \mathrm{Sn}, \mathrm{Sb}, \mathrm{Nd}, \mathrm{W}, \mathrm{Au}, \mathrm{Hg}, \mathrm{Tl}, \mathrm{Pb}, \mathrm{Bi}$, cuja baixa produção ou produção limitada poderá vir a impactar o mercado. Essa preocupação mereceu um número especial na revista Green Chemistry ${ }^{18,19}$ sobre elemental sustainability, estimulando o surgimento de iniciativas e propostas de processos sustentáveis e utilização responsável dos elementos químicos. Esse assunto é particularmente importante para o Brasil, que detém grandes riquezas minerais, como é o caso das terras raras, mas continua sendo mero exportador de commodities e produtos minerais com baixo valor agregado. Atualmente o mercado de terras raras é monopólio da China. E, particularmente importante é o neodímio, usado nos superimãs do tipo $\mathrm{Nd}_{2} \mathrm{Fe}_{14} \mathrm{~B}$, que estão entre os principais componentes de geradores e conversores de energia elétrica e eólica, e nos amplificadores de som. O lantânio faz parte dos catalisadores de craqueamento na indústria petroquímica. Outras terras raras atuam em sistemas de transmissão de sinais, e formação de imagens, e estão presentes em todos os celulares e smartphones. O nióbio é outra riqueza do Brasil, que detém mais de $95 \%$ das reservas mundiais. Esse elemento é usado em supercondutores, e tem um grande potencial de ser explorado tecnologicamente.

No Brasil ainda é comum a exploração mineral predatória ou com baixa tecnologia, provocando danos irreparáveis ao meio ambiente 


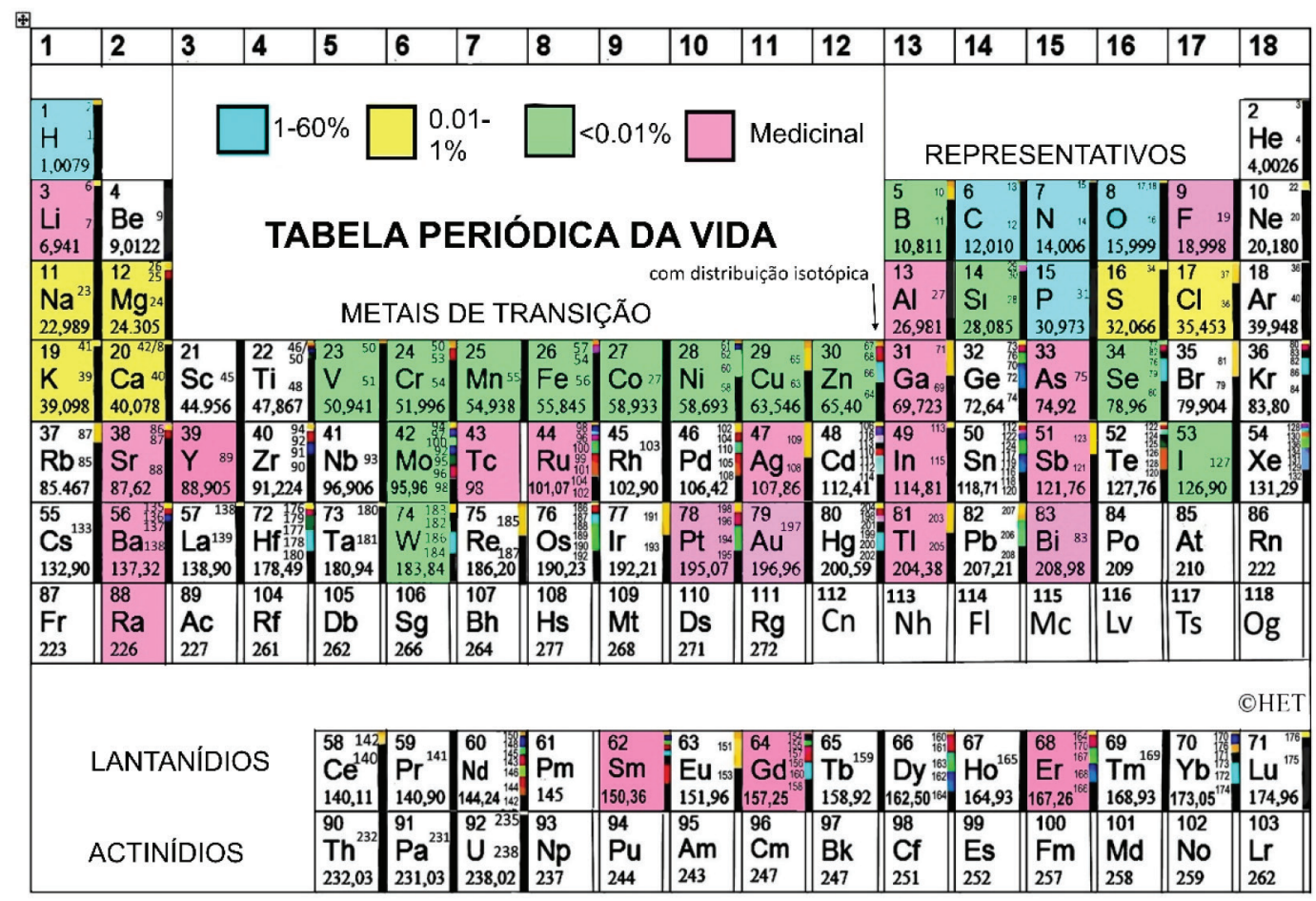

Figura 4. Tabela Periódica da Vida, mostrando os elementos de constituição $C, N, O, H, P$ que compõem de 1 a $60 \%$ do organismo, depois os elementos eletrolíticos e de suporte, como $\mathrm{Cl}, \mathrm{Na}, \mathrm{K}, \mathrm{Mg}$ e Ca, presentes em teores de 0,01 a 1\%, e os elementos traço que ocorrem abaixo de 0,01\% mas respondem por grande parte da atividade enzimática atuando diretamente no sítio ativo ou como cofatores. Os elementos usados na medicina atual também estão indicados na Tabela.

e colocando em risco a vida da população. Em contraponto, um dos aspectos que está em pauta em todo o mundo é a mineração urbana, atividade voltada para a extração e reaproveitamento dos elementos químicos, como forma de preservar os recursos naturais e promover a despoluição provocada pelos descartes da indústria eletro-eletrônica. ${ }^{19,20}$ Pensar na Tabela Periódica, com seus elementos, recursos e estratégias, é um passo importante em rumo à sustentabilidade mineral.

\section{CONCLUSÃO}

O Ano Internacional da Tabela Periódica ${ }^{21,22}$ é um estímulo e oportunidade para reflexão, colocando a Química no centro da atenção, com suas implicações de natureza histórica, econômica, social e futurística. Nesse contexto, grandes nomes que já foram citados merecem ser relembrados, e as noções da atomística quântica embutida na Tabela Periódica precisam ser incorporadas no ensino em todos os níveis, para propagar uma compreensão correta dos elementos e da própria Química. Por isso, esta iniciativa da ONU deve ser celebrada pela sociedade. A Tabela Periódica é uma grande conquista da Ciência.

\section{AGRADECIMENTOS}

Ao apoio da FAPESP - Projeto Temático 2013/24725-4 e CNPq 405301/2013-8 (Projeto de Tecnologia Mineral - Terras Raras), e aos colegas Alceu T. Silveira Jr, Fernando M. de Melo e Delmarcio G. da Silva pela leitura crítica deste artigo.

\section{REFERÊNCIAS}

1. UNESCO. 2019 - International Year of the Periodic Table of Chemical Elements. http://www.unesco.org/new/en/brasilia/about-this-office/ prizes-and-celebrations/2019-international-year-of-the-periodic-tableof-chemical-elements/. acessada em fevereiro de 2019.
2. Mendelejew, D.; Zeitsch.Chem. 1869, 12, 405.

3. Tolentino, M.; Rocha, R. C.; Chagas, A. P.; Quim. Nova 1997, $20,103$.

4. Greenberg, A.; Trad. Toma, H. E., Corio, P.; Osório, V. K. L. Uma breve história da Química, Edgard Blucher, São Paulo, 2009.

5. Ihde, A. J.; The development of modern chemistry, Harper \& Row, New York, 1964.

6. Toma, H. E.; Nanotecnologia molecular - materiais e dispositivos, Edgard Blucher, São Paulo, 2016.

7. Couter, P. L.; Burreson, J.; Trad. Borges, M. L. X.; Os botões de Napoleão. Jorge Zahar, Rio de Janeiro, 2003.

8. Gray, T.; Trad. Toma, H. E.; Os Elementos, Edgard Blucher, São Paulo, 2011.

9. Meyer, L.; Liebigs Ann. Chem. 1870, 7, 354.

10. Longuet-Higgins, H. C.; J. Chem. Ed. 1957, 34, 30.

11. Deming, H.; General Chemistry: an elementary survey, John Wiley \& Sons, New York, 1923.

12. Fluck, E.; Pure App. Chem. 1988, 60, 431.

13. Leach, M. R.; The internet data base of periodic tables. https://www. meta-synthesis.com/webbook/35_pt/pt_database.php, acessada em fevereiro de 2019.

14. Jürgen, H.; Seeger, Q.; The periodic table through history: Who charted the elements? Wiley VCH, 2007.

15. IUPAC; The periodic table of isotopes. 2011.

16. Toma, H.; Estrutura atômica, ligações e estereoquímica, Edgard Blucher, São Paulo, 2018.

17. Toma, H.; Química Bioinorgânica e Ambiental, Edgard Blucher, São Paulo, 2015.

18. Hunt, A.; Matharu, A.; King, A.; Clark, J.; Green Chem. 2015, 17, 1949.

19. Toma, H. E.; Green Chem. 2015, 17, 2027.

20. Condomitti, U.; Almeida, S. N.; Silveira, A.T.; de Melo, F. M.; Toma, H. E.; J. Braz. Chem. Soc., 2018, 29, 948.

21. Szuromi, P.; Science, 2019, 363, 464.

22. Editorial; Nature, 2019, 565, 535. 